\title{
Effects of Extraction and Nonextraction Treatment on Third Molar Angulation
}

\author{
${ }^{1}$ Ajay Sudhakar Nitturkar, ${ }^{2}$ Sachin Doshi, ${ }^{3}$ Ravindranath V Krishnan, ${ }^{4}$ Girish Karandikar \\ ${ }^{5}$ Samay Tahilramani, ${ }^{6}$ Bhavisha Gandhi
}

\begin{abstract}
Objective: To compare the angular changes in the developing third molars in both first premolar extraction and nonextraction cases and to determine if premolar extraction results in greater mesial movement of mandibular buccal segment and also causes favorable rotational changes in the third molar tip, which can improve later eruption of the third molars.
\end{abstract}

Materials and methods: Pretreatment (T1) and post-treatment (T2) panoramic radiographs were obtained 31 subjects were taken who had been treated by extraction of all first premolars and for 21 subjects treated with nonextraction theray. Occlusal plane was used to measure and compare the changes in the angles of the developing maxillary and mandibular third molars.

Results: The mean uprighting of the third molars seen in the extraction group was $8.7^{\circ} \pm 10.29^{\circ}$ and $2.97^{\circ} \pm 11.11^{\circ}$ on the right side, and $5.14^{\circ} \pm 9.04^{\circ}$ and $2.77^{\circ} \pm 12.10^{\circ}$ on the left side following treatment (T2 - T1). For the nonextraction group, the mean difference was $-1.52 \pm 6.43$ and $-6.430 \pm$ $12.21^{\circ}$ on the right side, and $-3.90^{\circ} \pm 7.67^{\circ}$ and $-5.7^{\circ} \pm 7.23^{\circ}$ on the left side. There was a statistically significant difference between the groups $(p<0.001)$.

Conclusion: Premolar extractions had a positive influence on the developing third molar angulations. Nonextraction therapy did not have any adverse effects.

Keywords: Premolar extractions, Third molar angulations, Orthopantomogram.

How to cite this article: Nitturkar AS, Doshi S, Krishnan RV, Karandikar G, Tahilramani S, Gandhi B. Effects of Extraction and Nonextraction Treatment on Third Molar Angulation. J Contemp Dent 2015;5(1):17-21.

Source of support: Nil

Conflict of interest: None

\section{INTRODUCTION}

Impactions of third molars are one of the major dilemma that the dental professions are facing ${ }^{1}$ with evolutionary changes being cited as a significant cause. The effect

\footnotetext{
${ }^{1,5,6}$ Postgraduate Student, ${ }^{2}$ Senior Lecturer

${ }^{3}$ Professor and Head, ${ }^{4}$ Professor

${ }^{1}$ Department of Orthodontics, MGM Dental College and Hospital, Navi Mumbai, Maharashtra, India

${ }^{2-6}$ Department of Orthodontics and Dentofacial Orthopedics, MGM Dental College and Hospital, Navi Mumbai, Maharashtra, India

Corresponding Author: Ajay Sudhakar Nitturkar, Postgraduate Student, Department of Orthodontics, MGM Dental College and Hospital, Navi Mumbai, Maharashtra, India, Phone: 020243513038, e-mail: drajaynitturkar@gmail.com
}

of third molars on the relapse of mandibular incisor crowding following the termination of retention in orthodontically treated patients has been a subject of much assumption.

The orthodontist should be aware of the relationship of the third molars to the remaining teeth in the dental arch. Most mandibular third molar studies have concentrated on the influence that the third molars have on the rest of the dentition rather than on the control that the rest of the dentition has on the third molars. ${ }^{2}$ The causes for third molar impaction and prediction of third molar eruption have also been studied extensively. In contrast, the effect of orthodontic treatment on the developing third molars has not been subjected to investigation.

It is often not easy to predict the fate of the third molars since the second molars of an average 12-year-old orthodontic patient have not yet erupted and the third molars have an inadequate amount of calcification at that time. Because this is usually considered the optimal age for treatment of most malocclusions, it is significant to know whether and how the third molars are developing before starting an orthodontic treatment plan. ${ }^{3}$

Developing third molars constantly change their angular positions ${ }^{4}$ and keep changing their important pre-eruptive rotational movements. ${ }^{5,6}$ These rotational movements happens when the third molar buds are in close proximity to the second molars. Richardson ${ }^{6}$ found that there was an average change of $11.2^{\circ}$ (20$42.5^{\circ}$ ) of the mandibular third molar between 10 and 15 years of age with respect to the mandibular plane. This indicates a tendency for the tooth to become more upright, with the angle of the mandibular third molar to the mandibular plane tending to decrease. There are strong chances that appliance therapy that holds back the mandibular molars or tends to actively tips them distally may have an effect of encouraging abnormal rotational movements of the third molar crown and, thereby increase the possibility of impaction. ${ }^{5}$ On the other hand, extraction of premolars might result in favorable mesial movement and uprighting rotational changes in the developing third molars, thereby causing an increase in the possibility of eruption. Extraction of premolars to allow mesial drifting of the buccal segment has been the subject of many investigations. ${ }^{5,9-27}$ 
The purpose of the present study was to find out whether extraction of the first premolars results in more mesial movement of the buccal segment and are responsible of favorable rotational changes in the third molar tip. This study evaluated the changes in the third molar angulations relative to a reference plane and to the second molar long axis. These changes were compared in patients treated with and without extraction of first premolars.

\section{MATERIALS AND METHODS}

A sample of 52 patients who had undergone fixed orthodontic treatment (preadjusted edgewise mechanotherapy) at the Department of Orthodontics and Dentofacial Orthopedics, MGM Dental College and Hospital, Navi Mumbai, Maharashtra, India, were selected for the study. Pretreatment (T1) and post-treatment (T2) orthopantomogram (OPG) were taken of 31 subjects who had been treated with the extraction of all first premolars (group 1) and 21 subjects who had been treated with nonextraction therapy (group 2).

\section{Inclusion Criteria}

- Fully unerupted third molars could be seen on an OPG in mesioangular positions. Not more than two thirds of the root development of the third molars had taken place.

- Class I dental malocclusion was present with a moderate anchorage requirement.

- Treatment of the extraction cases included full treatment of patients having requirement of closure of all the extraction spaces.

- The total treatment time in both the extraction and nonextraction cases was considered to be less than 24 months.

\section{Exclusion Criteria}

Patients with class II malocclusion requiring extraction of the second premolars and molar protraction were excluded from this study. Class I maxillomandibular protrusion (high anchorage need) cases requiring anchorage preparation were also excluded because the distal tipping of the terminal molars could have a negative influence on the third molar angulations.

\section{Method}

A sample of 52 orthodontically treated individuals patients were collected, among the 52 selected patients 31 were treated with premolar extractions and 21 patients were treated without any extraction. All the cases that were selected were skeletal class I malocclusion with mean age of 12.3 years (SD 1.8) pretreatment and 15.2 years (SD 1.7) post-treatment. All OPG's were taken by the same machine. Manual tracings were done for 3rd molars, 1st molars and 2nd premolars, Occlusal plane was constructed as shown in Figure 1, the changes in angles were measured by subtracting pretreatment values from the post-treatment values, which were then taken as the change in third molar angulation during treatment. For all the radiographs that were studied, increased angle indicated a favorable change in maxillary third molar angulation, while a decreased angle will indicate a favorable change in mandibular third molars. The changes for each group were compared for statistical difference using unpaired t-test (Table 2) at $<0.05$ significance level which was followed by the Mann-Whitney test which was used to evaluate treatment changes (Table 3).

The outlines of the second and third molars and their long axes were drawn on the tracing sheet. The long-axis of the second molar was traced from the midocclusal point through the midpoint of the root bifurcation and the midpoint between the mesial and distal root tips. The long axes of the third molar buds were drawn by the line bisecting a line connecting the mesial and distal outlines of the cervical areas. The following measurements were made as shown in Figure 1.

- The outer angles formed by the third molar axes to the occlusal plane on both the right and left sides.

- An increase in the angle of the third molar to the occlusal plane (OP), which would indicate an improvement in the position of the third molar the differences which can be seen clearly in the pretreatment OPG (Fig. 2) and the post-treatment OPG (Fig. 3).

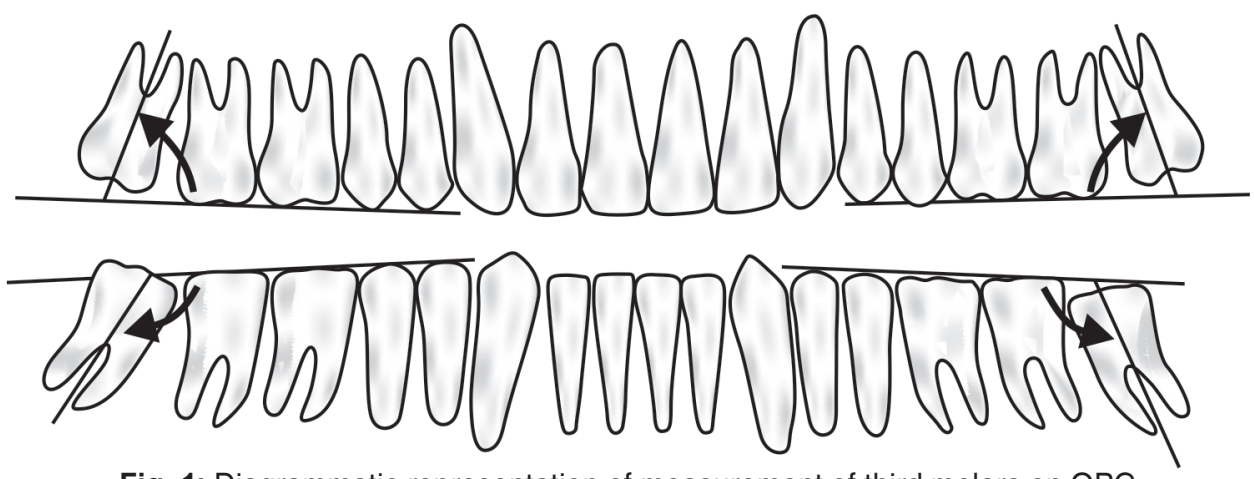

Fig. 1: Diagrammatic representation of measurement of third molars on OPG 


\section{RESULTS}

Comparison of the extraction and nonextraction groups showed no significant differences (Table 1). Tables 2 and 3 show the details of unpaired t-test and MannWhitney test respectively. The mean difference (T2-T1) in third molar angulation to the OP in the extraction group was $8.70^{\circ} \pm 10.29^{\circ}$ for the maxillary right side, and for the nonextraction group the mean difference was $-1.52^{\circ} \pm 6.43^{\circ}$ on the maxillary right side. This difference was statistically significant $(\mathrm{p}<0.05)$. The mean difference (T2-T1) in third molar angulation with respect to the $\mathrm{OP}$ in the extraction group was $5.14^{\circ} \pm 9.04^{\circ}$ on the maxillary left side, and for the nonextraction group the mean difference was $-3.90^{\circ} \pm 7.67^{\circ}$ on the maxillary left side. This was a statistically significant difference ( $\mathrm{p}<0.05)$.

The mean difference (T2-T1) in third molar angulation to the OP in the extraction group was $2.97^{\circ} \pm 11.11^{\circ}$ for the mandibular right side, and for the nonextraction group the mean difference was $-6.43^{\circ} \pm 12.21^{\circ}$ on the mandibular right side. This difference was statistically significant $(\mathrm{p}<0.05)$. The mean difference (T2-T1) in third molar angulation with respect to the OP in the extraction group was $2.77^{\circ} \pm 12.10^{\circ}$ on the mandibular left side, and for the nonextraction group the mean difference was $-5.57^{\circ} \pm 7.23^{\circ}$ on the mandibular left side. This was a statistically significant difference $(\mathrm{p}<0.05)$.

\section{DISCUSSION}

Third molar impaction is one of the most commonly encountered clinical problems; if third molar eruption

Table 1: Mean scores of change in third male inclimation in extraction and nonextraction treated patients

\begin{tabular}{llllll}
\hline & \multicolumn{3}{c}{ Group } \\
\cline { 2 - 3 } Variable and side & \multicolumn{2}{c}{ Extraction } & & \multicolumn{2}{c}{ Nonextraction } \\
\cline { 2 - 3 } \cline { 5 - 6 } Mean & $S D$ & & Mean & $S D$ \\
\hline Maxillary right & $8.70^{\circ}$ & $10.29^{\circ}$ & & $-1.52^{\circ}$ & $6.43^{\circ}$ \\
Maxillary left & $5.14^{\circ}$ & $9.04^{\circ}$ & & $-3.90^{\circ}$ & $7.67^{\circ}$ \\
Mandibular right & $2.97^{\circ}$ & $11.11^{\circ}$ & & $-6.43^{\circ}$ & $12.21^{\circ}$ \\
Mandibular left & $2.77^{\circ}$ & $12.10^{\circ}$ & & $-5.57^{\circ}$ & $7.23^{\circ}$ \\
\hline
\end{tabular}

Table 2: Unpaired t-test

\begin{tabular}{lll}
\hline$t$ - value & $p$-value & Difference \\
\hline 3.985 & 0.0002 & Significant \\
3.694 & 0.0006 & Significant \\
2.830 & 0.0068 & Significant \\
2.820 & 0.0069 & Significant \\
\hline
\end{tabular}

Table 3: Mann-Whitney test

\begin{tabular}{lll}
\hline z-value & $p$-value & Difference \\
\hline-3.823 & 0.0001 & Significant \\
-3.593 & 0.0003 & Significant \\
-2.726 & 0.0064 & Significant \\
-2.695 & 0.0070 & Significant \\
\hline
\end{tabular}

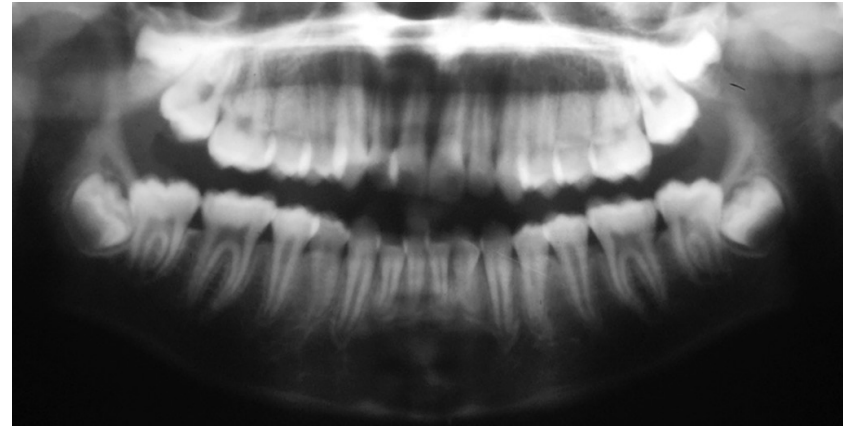

Fig. 2: Pretreatment OPG

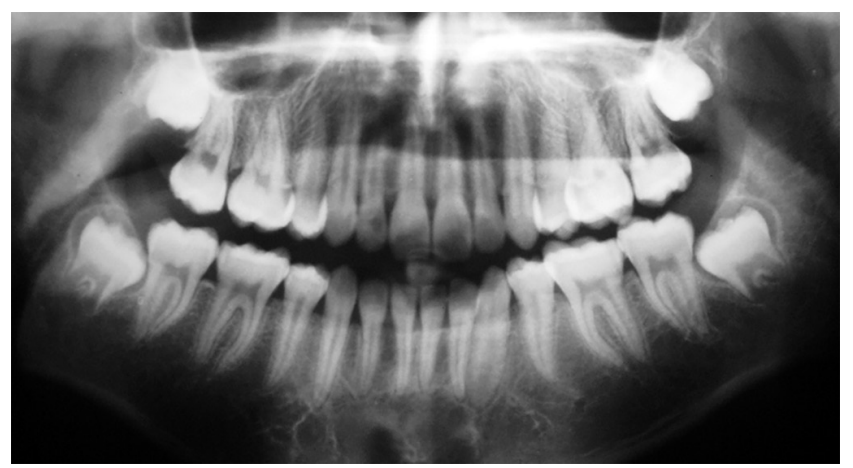

Fig. 3: Post-treatment OPG

can be detected at an early age during the course of orthodontic treatment then later occurrences of difficult impactions can be avoided. The subjects of this study ranged in age from 11 to 16 years with a mean age of about 12 years; during this time, the third molar bud is developing and is undergoing important rotational pre-eruptive movements. 5,6 Therefore, patients in this age group were selected to determine whether the treatment protocol (extraction or nonextraction) had any favorable effect on the rotational, uprighting, and pre-eruptive movements taking place at the given time.

\section{Changes with Extraction Treatment}

A significant improvement in third molar angulation following extraction treatment was seen on both the right and left sides in both the arches. Similar uprighting or improvements in third molar angulations with extraction of premolars were also reported in previous studies. ${ }^{18,21-27}$ Elsey and Rock, ${ }^{20}$ using the midline reference plane on panoramic radiographs showed an improvement in third

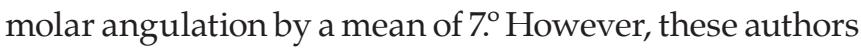
did not compare the changes on the right and left sides and no comparisons were made with a representative group of nonextraction patients.

The present findings contradict some of the previous studies which were conducted by Graber and Kaineg ${ }^{13}$ and $\mathrm{McCoy}^{9}$ which showed that premolar extraction probably does not enhance normal eruption of third molars. The changes seen in the present study may be attributed to the mesial movement of the buccal segment 
following space closure and an increase in the space for the rotational uprighting movements of the third molar. Growth changes in the retromolar area might have also contributed to increasing the space for the third molar, as was previously confirmed by Capelli. ${ }^{16}$

\section{Changes with Nonextraction Treatment}

Third molar angulation increased minimally in maxillary arch and showed a significant increase in mandibular arch. Hence, the third molar angulations were more or less maintained in all cases and showed very minimal improvement when treatment was done with the nonextraction technique. The present findings corroborate those of previous studies, ${ }^{14,15}$ in which improvements in some of the third molar angulations occurred, but they were significantly less than those seen in extraction cases.

The present results are in contrast to the findings of Yigit et $\mathrm{al}^{23}$ who showed a worsening of mandibular third molar angulations with nonextraction treatment. Silling ${ }^{5}$ stated that nonextraction therapy by holding back or distally tipping the mandibular first and second molars increased the chances of third molar impaction. The slight changes taking place in the absence of extractions could be attributed to the growth taking place in the retromolar area.

\section{Clinical Implications}

Premolar extractions in preadolescent orthodontic patients have a positive influence on third molar angulations by promoting mesial migration and improving the possibility that the third molars will erupt in acceptable positions. Hence, this aspect of dental practice needs to be more widely appreciated in the planning of treatment for children.

Although, it is not possible to predict from the results how many third molars would erupt fully later on it is clear that the improved positions would facilitate surgery for many of those teeth that did ultimately require removal. The authors recommend that third molar angulations be included in the treatment planning of borderline extraction cases. When third molar angulations are seen to be less favorable for eruption although their chances for eruption (as dictated by other factors) can be predicted as high, extracting premolars in such cases will improve their angulations making them favorable for eruption.

The orthodontist must be cautious in evaluating the positions of the third molars when planning treatment since their final characteristics are late to develop. In patients in whom orthodontic treatment is concluded before complete third molar development regardless of whether premolar extractions have been done or not, the patient should be recalled when he or she is older for radiographic examination to assess the development of the third molars. If the third molars are becoming impacted, referral to an oral surgeon for surgical removal should be made.

\section{CONCLUSION}

- Premolar extractions had a positive influence on the developing third molar angulations, and these improved angulations might favor third molar eruptions later in life.

- Borderline cases with favorable third molar angulations can benefit by premolar extractions.

- If the third molars do become impacted after treatment, the improved angulations can help facilitate their surgical removal.

- Preserving the premolars as in nonextraction treatment may result in extraction of the third molars later, so the use of the term nonextraction in such cases should also be questioned.

\section{REFERENCES}

1. Jain S, Valiathan A. Influence of first premolar extraction on mandibular third molar angulation. Angle Orthod 2009;79(6): 1143-1148.

2. Peterson LJ. Rationale for removing impacted teeth: when to extract or not to extract. J Am Dent Assoc 1992;123(7):198-204.

3. Staggers JA, Germane N, Fortson WM. A comparison of effects of first premolar extractions on third molar angulations. Angle Orthod 1992;62(2):135-138.

4. Richardson M. Late third molar genesis: its significance in orthodontic treatment. Angle Orthod 1980;50(2):121-128.

5. Silling G. Development and eruption of the mandibular third molar and its response to orthodontic therapy. Angle Orthod 1973;43(3):271-278

6. Richardson ME. The early developmental position of the lower third molar relative to certain jaw dimensions. Angle Orthod 1970;40(3):226-230.

7. Ledyard BC. A study of the mandibular third molar area. Am J Orthod Dentofac Orthop 1953;39(5):366-373.

8. Herzberg BL. Extraction in orthodontic treatment, cases in which extraction of the four first bicuspids is advisable. Dent Clin North Am 1960;4:789-794.

9. McCoy JR. A study of growth potential; from observations made in over 50 years of orthodontic practice. Am J Orthod Dentofac Orthop 1965 Feb;51:79-97.

10. Faubion BH. Effect of extraction of premolars on eruption of mandibular third molars. J Am Dent Assoc 1968;76(2):316-320.

11. Dierkes DD. An investigation of the mandibular third molars in orthodontic cases. Angle Orthod 1975;45(3):207-212.

12. Kaplan RO. Some factors related to mandibular third molar impaction. Angle Orthod 1975;45(3):153-158.

13. Graber TM, Kaineg TF. The mandibular third molar: its predictive status and role in lower incisor crowding. Proc Finn Dent Soc 1981;77(1-3):37-44.

14. Forsberg CM, Vingren B, Wesslen U. Mandibular third molar eruption in relation to available space as assessed on lateral cephalograms. Swed Dent J 1989;13(1-2):23-31.

15. Richardson ME. The effect of mandibular first premolar extraction on third molar space. Angle Orthod 1989;59(4): 291-294. 
16. Capelli J Jr. Mandibular growth and third molar impaction in extraction cases. Angle Orthod 1991;61(3):223-229.

17. Swessi DM, Stephens CD. The spontaneous effects of lower first premolar extraction on the mesiodistal angulation of adjacent teeth and the relationship of this to extraction space closure in the long term. Eur J Orthod 1993;15(6):503-511.

18. Castella P, Albright RH Jr, Straja S, Tuncay OC. Prediction of mandibular third molar impaction in the orthodontic patient from a panoramic radiograph. Clin Orthod Res 1998;1(1):37-43.

19. Erdem D, Ozdiler E, Memikoglu UT, Baspinar E. Third molar impaction in extraction cases treated with the Begg technique. Eur J Orthod 1998 Jun;20:263-270.

20. Elsey MJ, Rock WP. Influence of orthodontic treatment on development of third molars. Br J Oral Maxillofac Surg 2000; 38(4):350-353.

21. Gungormus M. Pathological status and changes in mandibular third molar position during orthodontic treatment. J Contemp Dent Pract 2002;15(2):11-22.
22. Kim T-W, Årtun J, Behbehani F, Artese F. Prevalence of third molar impaction in orthodontic patients treated nonextraction and with extraction of 4 premolars. Am J Orthod Dentofac Orthop 2003 Feb;123(2):138-145.

23. Yigit M, Gokce D, Kocadereli I, Tasar F. The effects of first premolar extractions on third molar angulations. Angle Orthod 2005;75(5):719-722.

24. Årtun J, Thalib L, Little RM. Third molar angulations during and after treatment of adolescent orthodontic patients. Eur J Orthod 2005;27(6):590-596.

25. Behbehani F, Årtun J, Thalib L. Prediction of mandibular third molar impaction in adolescent orthodontic patients. Am J Orthod Dentofac Orthop 2006;130(1):47-55.

26. Olive RJ, Basford KE. Transverse dentoskeletal relationships and third molar impaction. Angle Orthod 1981;51(1):41-47.

27. Larheim TA, Svanaes DB. Reproducibility of rotational panoramic radiography: mandibular linear dimensions and angles. Am J Orthod Dentofac Orthop 1990 July;90(1):45-51. 